\title{
Influence of homelessness on acute admissions to hospital
}

\author{
Tom Lissauer, Sharon Richman, Marina Tempia, Sue Jenkins, Brent Taylor
}

\begin{abstract}
The aim of this study was to look at the influence of homelessness on acute medical admissions. A prospective casecontrolled study was therefore performed on all homeless children admitted through the accident and emergency department over one year, comparing them with the next age matched admission from permanent housing. Assessments made were: whether homelessness or other social factors influenced the doctors' decision to admit; differences in severity of illness; length of stay; and use of primary care. The admitting doctors completed a semistructured questionnaire during admission about social factors that influenced their decision to admit and graded the severity of the child's illness. The length of hospital stay was recorded. The family's social risk factors and accommodation were assessed at a home visit using a standardised questionnaire and by observation.
\end{abstract}

Seventy homeless children were admitted. Social factors influenced the decision to admit in $77 \%$ of homeless children and $43 \%$ of controls. More of the homeless children were only mildly ill (33/70) than those from permanent housing (21/70), although three of the homeless children died of overwhelming infections compared with none of the controls. Among homeless families many were recent immigrants $(44 \%)$. There was a marked increase in socioeconomic deprivation, in major life events in the previous year (median score $3 v 1$ ), and in maternal depression $(27 \% v 8 \%)$. Referral to the hospital was made by a general practitioner in only $5 / 50(10 \%)$ of homeless compared with $18 / 50(36 \%)$ of controls.

Social factors were an important influence on the decision to admit in over three quarters of the homeless children and resulted in admission when less severely ill even when compared with admissions from an inner city population. Even though there was marked social deprivation among the homeless families, the decision to admit was based on vague criteria that need to be further refined.

(Arch Dis Child 1993; 69: 423-429)

Over the last decade the number of households accepted by local authorities in England as officially homeless under the terms of the 1985 Housing Act rose from 53110 in 1978 to
145800 in $1990 . .^{1}$ Over $90 \%$ of the officially homeless are single parents or couples with dependent children or pregnant women, and many are placed in temporary accommodation such as bed and breakfast hotels while awaiting permanent housing. During the period of this study, about 1200 households were, at any one time, placed in hotels near to St Mary's Hospital, London by up to 15 of London's 32 local authorities.

It is widely believed that homelessness has adverse effects on children's health and development. ${ }^{23}$ The Audit Commission has stated that bed and breakfast hotels are 'unsuitable for family life', ${ }^{4}$ and health professionals have described the living conditions as deplorable and a risk to health. ${ }^{5-7}$ Unfortunately these reports are anecdotal and do not provide a comparison with residents in permanent housing. Little is known about the influence of homelessness on acute admission to hospital. A study in Glasgow showed that children from deprived areas were nine times as likely to be admitted to hospital as other children. ${ }^{8}$ At St Mary's Hospital, London, the overall admission rate to hospital is 4.5 times as high for homeless as local residents and for children the admission rate is more than double. ${ }^{9}$ Homeless children are also disproportionately represented among those referred to the hospital's Paediatric Home Care Unit with burns and scalds. ${ }^{10}$ The reason for this increased admission rate is unclear. The reports by health professionals would suggest a high incidence of ill health and the problems of poor accommodation and other social risk factors may make it difficult or impossible to care for a sick child at home. Poor access to primary care may also be important.

The aim of this study was to assess the influence of homelessness on acute admission of children to hospital. Factors examined were whether homelessness and other social factors influenced the decision to admit the child; whether there were differences in the severity of the child's illness; the length of hospital stay and use of primary care; and the appropriateness of the child's management as perceived by the families themselves. The families' housing conditions and social risk factors were assessed independently to see if they did actually differ from those of the local inner city residents in permanent housing

\section{Subjects and methods}

SUBJECTS

All children under 5 years old living in temporary hotel accommodation and admitted 
to St Mary's Hospital with acute nonsurgical conditions over a one year period from 1989-90 were enrolled by checking their address against a register of bed and breakfast hotels. The next age matched child admitted to the same ward from a permanent home address with an acute medical condition or accident was identified as a control. No child was included in the survey more than once.

Data were collected by means of two precoded questionnaires. The first was completed in hospital from the notes and included data relating to the presenting illness. The admitting paediatric doctor was then interviewed while the child was on the ward, using a semistructured questionnaire, and asked whether, and to what extent, social factors had contributed to the decision to admit the child and to grade the severity of the illness on admission on a four point scale. The questionnaire was based on a pilot study of 40 children in which doctors were asked to list any social factors that had influenced their decision to admit to hospital. The staff were told that a study was being performed about social factors affecting the admission of children to hospital, without specific reference to homelessness. The length of hospital stay was recorded after discharge.

A second structured questionnaire was completed with the mother at a home visit by a research health visitor (MT) 4-7 days after the child's discharge from hospital. This was designed to examine three main areas:

(1) The acute illness including the mode of presentation to hospital, the duration of the child's acute illness, and the family's use of primary health care. Families were asked about continuing medical problems after discharge and their view on the appropriateness of the length of their child's stay on the wards.

(2) The family's demographic and social risk factors including details of the family composition, past and present housing, socioeconomic conditions, recent life events, and an assessment of maternal depression. Details about life events were collected using the list validated by Beautrais et $a l^{11}$ and maternal depression was assessed using a modified version of the Hospital Anxiety and Depression Scale ${ }^{12}$ in which a score is constructed by summing the number and severity of symptoms reported by the child's mother.

(3) Problems caused by accommodation, including the mother's perception and the health visitor's observation of the standard of accommodation and adequacy of play space.

STATISTICAL ANALYSIS

Statistical analysis was with a $\chi^{2}$ or odds ratio for essential comparisons between the homeless and controls. A Mann-Whitney U test was used to compare the number of life events between homeless and control families. No statistical tests were performed on descriptive demographic data.

\section{Results}

HOSPITAL DATA

Medical data was collected from all 70 children admitted during the one year study period who were living in temporary hotel accommodation and from 70 controls from permanent accommodation. During this time there were 1755 acute medical admissions. There was a preponderance of boys, $65 \%$ of the homeless and $62 \%$ of controls, with $70 \%$ of the children being under 2 years old. The mother's country of birth of the homeless children varied during the year with a sequence of families from Bangladesh (7\%), then Ireland (31\%), followed by Kurdish and Somali refugees (19\%). Only $33 \%$ of the mothers were born in the UK. This contrasted with the control children, $67 \%$ of whose mothers came from the UK, 3\% from Bangladesh, 3\% from Ireland, and the remainder from other countries.

Homeless children were more likely to be admitted with infectious diseases, especially gastroenteritis or respiratory tract infections (table 1). Accidental injuries were also more common. The numbers of children in each diagnostic group was small and the differences between homeless and control children did not reach conventional levels of statistical significance.

The severity of the children's illness was graded by the admitting junior staff as not ill, mild, moderate, or severe (table 2). Seven of the homeless and eight of the controls were not ill but were admitted for failure to thrive or other problems. More of the homeless children were graded as being mildly ill, and more of the controls were moderately ill. The odds ratio for homeless children being only mildly or not acutely ill was 1.89 (confidence interval (CI) 0.96 to 3.69 ). However, three children died, all of whom were homeless. Deaths were due to septicaemia or meningitis, two meningococcal and one pneumococcal. Three other children had meningitis, one homeless and two controls, but they made a full recovery.

Medical staff were questioned on the influence of social risk factors on their decision to admit individual patients (table 3 ). Overall, social factors were reported to have influenced their decision to admit in $77 \%(54 / 70)$ of homeless compared with $43 \%(30 / 70)$ of

Table 1 Principal diagnosis on hospital admission

\begin{tabular}{lcc} 
& $\begin{array}{l}\text { No (\%) homeless } \\
(n=70)\end{array}$ & $\begin{array}{l}\text { No (\%) controls } \\
(n=70)\end{array}$ \\
\hline Respiratory infection & $14(20)$ & $10(14)$ \\
Diarrhoea +l- vomiting & $18(26)$ & $11(16)$ \\
Other infections & $15(21)$ & $18(26)$ \\
Asthma & $3(4)$ & $5(7)$ \\
Accidents & $12(17)$ & $8(11)$ \\
Social & $2(3)$ & $2(3)$ \\
Other & $6(9)$ & $16(23)$ \\
\hline
\end{tabular}

Table 2 Severity of illness graded by admitting doctor

\begin{tabular}{lcc} 
& $\begin{array}{l}\text { No (\%) homeless } \\
(n=70)\end{array}$ & $\begin{array}{l}\text { No (\%) controls } \\
(n=70)\end{array}$ \\
\hline Not ill & $7(10)$ & $8(11)$ \\
Mild & $33(47)$ & $21(30)$ \\
Moderate & $23(33)$ & $37(53)$ \\
Severe & $7(10)$ & $4(6)$
\end{tabular}


Table 3 Children in whom social factors influenced decision to admit

\begin{tabular}{lcc}
\hline Social risk & $\begin{array}{c}\text { Homeless } \\
(n=70)\end{array}$ & $\begin{array}{c}\text { Controls } \\
(n=70)\end{array}$ \\
\hline Single parent & 20 & 7 \\
Language problems & 6 & 6 \\
Generally poor home circumstances & 48 & 8 \\
Homelessness & 21 & 0 \\
Parent 'not coping' with ill child & 35 & 22 \\
Overall: social risk factors & 54 & $30(\mathrm{p}<0.001)$ \\
$\quad$ influenced admission & &
\end{tabular}

controls. This difference is statistically significant $\left(\chi^{2}=15 \cdot 7,1 \mathrm{df}, \mathrm{p}<0 \cdot 001\right)$. 'Generally poor home circumstances' rather than 'homelessness' itself was seen as most important, followed by a perception that the parent was not coping adequately with an ill child. In $20 \%$ of cases the doctor had not recognised that the family were in temporary accommodation.

The duration of children's stay in hospital showed a mean of 3.6 days (median 3.0 days) for homeless children compared with a mean of 4.5 days (median 3.0 days) for the controls. This corresponds with the homeless children generally being less ill but shows that they were not kept in hospital for a prolonged period because of home circumstances.

\section{HOME INTERVIEWS}

Home visits were completed for 50 homeless and their age matched control children. Twenty of the 70 homeless children were lost to follow up. Nine had moved or were not traceable, five families were out repeatedly at the appointed times, three declined to answer the questionnaire, and the families of the three children who died were not interviewed to avoid possible further distress. Of the 20 index children who were lost to follow up, none of their mothers were born in Bangladesh, nine were from the UK (45\%), eight were from Ireland $(40 \%)$, and three were Kurdish or Somali refugees $(15 \%)$. The country of birth of the families interviewed were therefore representative of the children admitted to hospital. All matching control families were contacted and interviewed. English was not the primary language in $32 \%$ $(16 / 50)$ of homeless and $22 \%(11 / 50)$ of control families. An interpreter was required in $10 \%(5 / 50)$ of the homeless and $4 \%(2 / 50)$ of control families; professional interpreters were needed for only three homeless Kurdish families.

\section{CHILD'S ILLNESS}

Most illnesses were acute but homeless children appeared more likely to have had their symptoms for longer before coming to hospital (table 4), although this difference was not statistically significant $\left(x^{2}=2 \cdot 67,2 \mathrm{df}, \mathrm{p}<0 \cdot 3\right)$. Fewer homeless children had a prior consultation with a general practitioner, $17 / 50$, compared with $29 / 50$ for controls, although all the homeless families were registered with a general practitioner. The decision to come to the hospital was taken more often by parents of homeless children than controls, $42 / 50$ as
Table 4 Characteristics of illness

\begin{tabular}{lll} 
& $\begin{array}{c}\text { Homeless } \\
(n=50)\end{array}$ & $\begin{array}{c}\text { Controls } \\
(n=50)\end{array}$ \\
\hline Duration of symptoms & & \\
$\quad<24$ hours & 16 & 23 \\
$\quad$ 1-3 days & 18 & 17 \\
$>3$ days & 16 & 10 \\
Prior consultation with general practitioner & 17 & 29 \\
Decision to come to hospital made by & 42 & 29 \\
$\quad$ Parents & 5 & 18 \\
General practitioner & 3 & 3 \\
Other & &
\end{tabular}

opposed to $29 / 50$ for controls, an odds ratio of $3 \cdot 80$ (CI 1.48 to $9 \cdot 75$ ).

ASSESSMENT OF HOSPITAL TREATMENT

At the interview after discharge all except one parent in each group felt that their child was either completely or almost back to normal. There were no significant differences using conventional testing between groups in their opinion of the duration of the stay in hospital. Most parents (43/50 homeless and 44/50 controls) felt that the length of time spent by their child in hospital had been 'about right'. Only three homeless and one control thought that the stay had been too long and that their child had been ready to come home sooner, while four homeless and five controls thought that their child had been discharged too soon.

\section{FAMILY HEALTH}

Maternal depression was significantly increased among the homeless mothers. Using the scoring system, $7 / 50(14 \%)$ of hotel mothers were clinically depressed and another five $(10 \%)$ were borderline, compared with no clinically depressed control mothers and $4 / 50(8 \%)$ who were borderline. There were significantly more homeless mothers with clinical depression than those with borderline or no depression (Fisher's exact test, $\mathrm{p}=0.006$ ).

\section{RECENT LIFE EVENTS}

Homeless mothers had experienced a median of three (range 2-7) significant life events compared with control mothers who experienced a median of one (range $0-6$ ) out of a maximum of 19 (table 5). This was a highly significant increase in the number of life events among the homeless mothers (Mann-Whitney $U$ test, $U=380.5, p<0.001)$. All but one homeless mother had moved home in the previous year compared with about a quarter of

Table 5 Life events in previous year

\begin{tabular}{lll} 
& $\begin{array}{c}\text { Homeless } \\
(n=50)\end{array}$ & $\begin{array}{c}\text { Controls } \\
(n=50)\end{array}$ \\
\hline Moved home & 49 & 13 \\
Immigrated to UK & 22 & 3 \\
Either partner changed job & 3 & 6 \\
Either partner lost job & 16 & 9 \\
Got married or divorced & 12 & 3 \\
Serious arguments & 17 & 7 \\
Assault on mother & 7 & 2 \\
Bereavement & 18 & 9 \\
Pregnancy & 28 & 27 \\
Involvement with court of law & 12 & 3 \\
Total median score (range) & $3(2-7)$ & $1(0-6)(p<0.001)$
\end{tabular}


controls and $44 \%(22 / 50)$ had emigrated to the UK. Three of these 50 mothers said that either they or their partner had changed their job and 16 jobs had been lost compared with $6 / 50$ changing jobs and nine redundancies among controls. Domestic arguments or violence were more common in homeless families: $34 \%$ of hotel mothers reported serious or prolonged arguments with their partner and $14 \%$ had been assaulted by their partner. Twice as many homeless mothers had suffered a bereavement. Pregnancy was equally common in the two groups and two in each group had had a miscarriage. Homeless mothers were also more likely to have been involved with a court of law.

\section{SOCIOECONOMIC STATUS (TABLE 6)}

Homeless mothers were less likely to go out to work: only $4 \%(2 / 50)$ were employed, all in part time work, whereas $34 \%$ (17/50) control mothers did full or part time work outside the home; two thirds (11/17) of whom had nonmanual occupations. There was also a marked difference in the proportion of fathers who were employed, with twice as many among the control families. To provide a more complete picture of socioeconomic status, mothers were questioned about their educational attainments. Homeless mothers had received less education, with $24 \%(12 / 50)$ reporting no formal schooling or primary education only, and only $6 \%(3 / 50)$ having had some form of higher education, compared with $20 \%$ (10/50) of controls.

There were also very marked financial differences between the groups. The mean gross earned income of the homeless families was f68 per week among those with jobs, but $82 \%$ (41/50) did not receive any earned income at all. Twenty eight percent $(14 / 50)$ of control families received no earned income and the mean gross weekly income of the remainder was $£ 242$. When social security benefits were included, the mean total income per week of a homeless family was $£ 83$, compared with $£ 207$ per week for controls. This information was obtained directly from the parents.

\section{HOUSING}

Homeless families had been in temporary accommodation for a median of eight months; $28 \%(14 / 50)$ had been homeless for under two months, but $18 \%(9 / 50)$ had been homeless for

Table 6 Family composition and socioeconomic conditions

\begin{tabular}{lcc}
\hline & $\begin{array}{c}\text { No (\%) } \\
\text { homeless } \\
(n=50)\end{array}$ & $\begin{array}{r}\text { No (\%) } \\
\text { controls } \\
(n=50)\end{array}$ \\
\hline $\begin{array}{l}\text { Parents } \\
\quad \text { Single parent }\end{array}$ & $25(50)$ & $20(40)$ \\
$\quad$ No contact with natural fathers & $13(26)$ & $6(12)$ \\
Employment & $2(4)$ & $17(34)$ \\
$\quad$ Mothers (full or part time) & $22(44)$ & $44(88)$ \\
$\quad \begin{array}{l}\text { Fathers (resident and non-resident) } \\
\text { No earned income }\end{array}$ & $41(82)$ & $14(28)$ \\
Education & $12(24)$ & $3(6)$ \\
$\quad$ No formal school or primary only & $3(6)$ & $10(20)$ \\
$\quad$ Higher education & & \\
Housing & $1(2)$ & $48(96)$ \\
$\quad \begin{array}{l}\text { Satisfactory play facilities (health } \\
\quad \text { visitor assessment) }\end{array}$ & & \\
\hline
\end{tabular}

over a year, and one for over two years. Changes of accommodation were frequent: $21 / 50$ had lived in their accommodation for under two months and 23/50 for under six months. Of the remaining six families, only one had been at the same address for more than a year. The mean time in the current accommodation was 3.5 months whereas the mean time in the current home in the control group was four years. Among the control families $18 / 50$ had lived in their homes for more than five years and $15 / 50$ from two to five years. Twenty four of the 50 control families lived in rented council accommodation, 20 in flats, and four in houses. Another four families lived in privately rented homes, eight in housing association premises, and 14 owned their homes. Altogether, 34/50 control families lived in flats and 16 in houses.

Problems experienced with housing reflected the nature of the accommodation (table 7). The commonest complaint of all mothers was lack of space. An 'overcrowding index' was calculated to give a more objective comparison: hotel families lived with a mean of 3.0 people per room (range $1.75-6.0$ excluding any kitchen, bathroom, or hallway) while controls had a mean of 1.4 people per room (range $0 \cdot 4-5 \cdot 0$ ). The majority of homeless families said that their child had nowhere safe to play; our interviewer's independent assessment of play facilities concluded that only $2 \%$ (1/50) of homeless children had satisfactory play facilities compared with $96 \%(48 / 50)$ of controls.

Both groups of mothers complained of isolation and noise. Lack of privacy was a problem mainly for homeless families as were problems with poor hygiene, cooking and laundry facilities, and, to a lesser extent, limited washing facilities. Mothers from permanent home addresses were more likely to complain that their accommodation was cold and/or damp. A few mothers in both groups $(8 / 50$ in homeless and $2 / 50$ controls) pointed out the cockroaches in the kitchen.

\section{Discussion}

Children from homeless families have been shown to make increased use of acute hospital services and have an increased rate of admission. Most of the children in this study were admitted to hospital with respiratory, gastrointestinal, or other infections. The sample size was too small to allow further analysis of admission after accidents, but a survey of all acute attendances to this hospital over one year showed that the proportion of children from homeless families with scalds and burns was doubled. ${ }^{13}$

Table 7 Housing complaints by mothers

\begin{tabular}{llr}
\hline & $\begin{array}{l}\text { No (\%) homeless } \\
(n=50)\end{array}$ & $\begin{array}{l}\text { No (\%) controls } \\
(n=50)\end{array}$ \\
\hline $\begin{array}{l}\text { Lack of space } \\
\text { Nowhere safe for children }\end{array}$ & $35(70)$ & $27(54)$ \\
$\quad$ to play & $34(68)$ & $7(14)$ \\
Isolated & $29(58)$ & $16(32)$ \\
Noisy & $19(38)$ & $15(30)$ \\
Lack of privacy & $16(32)$ & $7(14)$ \\
\hline
\end{tabular}


Overall the homeless children in this study were less ill than controls. The shorter hospital stay of homeless families reflects their being generally less ill but also shows that children were not kept in hospital for a prolonged period because they were homeless. It was reassuring to find that most families felt that the length of hospital stay was appropriate.

While we were not surprised to find the increased admission rate of mild illness among the homeless children, it was disturbing to find that three of the 70 children admitted from homeless families died from overwhelming infections. The risk of spread of serious infectious diseases in families living in overcrowded hotel rooms needs to be closely monitored. It seems likely that the mortality rate of $3 / 70$ admissions from homeless families is not generally representative, although this demands confirmation in other hospital populations.

Social factors influenced the medical staff's decision to admit to hospital in the majority $(77 \%)$ of admissions of homeless children compared with less than half in control children. However, it was the doctor's perception of the parent's difficulty in coping with the child's illness and poor home circumstances in general that had a greater influence rather than homelessness per se. Indeed the admitting doctor had not identified that the family was homeless in $20 \%$ of the families from temporary accommodation. This data was obtained using a semistructured questionnaire based on a pilot study in which admitting doctors were asked to list any social factors that had influenced their decision to admit 40 children. It was simply based on current clinical practice.

There has been considerable debate over whether the increased hospital attendance by the homeless reflects a lack of access to primary health care or increased illness. Both are likely to apply. Homeless families may have difficulty in registering with general practitioners and in obtaining access to primary care as they move home so frequently. In our study all the homeless families had a general practitioner, but nevertheless were less likely than permanent residents to consult their general practitioner. The reason for this was not clear. It seems that rather than return to their general practitioner for further consultation of continuing illness, more of the homeless families chose to come to the hospital. A recent survey found that $92 \%$ of homeless people in this area were registered with a general practitioner, but in $18 \%$ the practice was a long way from where they were staying. ${ }^{14}$ Among homeless adults there was both increased acute and chronic illness and greater use of both primary and hospital services. Since this study was completed a general practice surgery for homeless families has been established near the hospital to improve access to primary care.

The marked increase in the proportion of homeless mothers who were depressed, either clinically or borderline, was disturbing knowing that maternal depression has been shown to adversely affect the health and development of infants ${ }^{15}$ and children. ${ }^{16}$ Although we do not know about the mental health of these mothers before becoming homeless, there is a known association between lack of social support systems and maternal depression ${ }^{17}$ and it is likely that poor housing contributed to the higher number who were depressed. The rate of depression in both groups is lower than rates among mothers of young children found in other studies ${ }^{18}$ and may reflect the use of different scoring methods to assess depression. Our findings are in accord with the recent survey by Victor of the health status of adults in temporary accommodation in this area which found that their mental health morbidity was over twice that for the North West Thames region as a whole $(45 \% v 18 \%){ }^{14}$

Analysis of social risk factors revealed a worrying catalogue of the multiple facets of social deprivation experienced by homeless families. Many of the homeless families were recent immigrants, including refugees from war torn countries, resulting in a marked difference in ethnicity compared with the families in permanent housing. Half of homeless families were headed by a single parent; levels of education were low; parental employment, both maternal and paternal, were reduced and there was a very marked difference in income. Accommodation for the homeless revealed overcrowding with limited cooking and laundry facilities and virtually no play facilities for children. Many of the homeless families were further disadvantaged by their inability to speak fluent English. Homeless mothers had experienced on average twice as many significant life events in the previous year. While it was to be expected that homeless families would score higher in relation to moving home and immigration in the previous year, we also found that they had experienced many other disruptive life events, including a job loss of either partner, marriage or divorce, bereavement, serious arguments, assault on mother, and involvement with a court of law. Homelessness is associated with a very high incidence of life events each of which can be highly stressful for a family.

We have shown that social risk factors did influence the admitting doctors decision whether or not to admit a child to hospital. This is important as it results in an increased admission rate which places considerable extra demands for increased hospital provision and resources. It is clearly difficult for a doctor who does not know a family to assess a family's ability to cope with their sick child in a short time without asking questions that could be perceived as invading the family's privacy. Even with the homeless families in this study who we have shown were experiencing severe socioeconomic deprivation and a high rate of maternal depression, the admitting doctors appear to have mainly relied on their own intuition rather than any recognised criteria for deciding when to admit a child to hospital and had not always recognised that the family was in temporary accommodation.

\section{CONCLUSION}

In this investigation of factors associated with the acute admission of children to hospital we 
have demonstrated that those from homeless accommodation experienced more severe socioeconomic deprivation and higher rates of maternal depression and life events even when compared with children admitted from permanent housing in a deprived inner city population. Although homelessness is usually a transient state experienced by a widely heterogeneous group of people from many different backgrounds, in Britain it is a marker of severe, multiple deprivation. How this influences the decision to admit a child to hospital is complex. Clearly, further studies are needed to try and analyse which social risk factors are really important when considering whether or not to admit a child, and how such information can best be obtained. We believe that if this problem was specifically addressed useful information would be gained.

Although the total number of homeless households continues to increase, the use of bed and breakfast hotels has declined as less costly temporary accommodation, either privately leased or publicly owned, is used instead. In addition, there has been a shift from inner to outer London locations. In this study, placement in a bed and breakfast hotel served as a useful indicator of severe socioeconomic deprivation. As these and other severely disadvantaged families become more widely dispersed within the community, we will need to become more discerning in identifying the particular needs of such families when considering hospital admission. This makes it even more important for us to refine the complex interrelationship between social deprivation, clinical illness, and need for hospital admission.

We are grateful to the Homelessness Project and the Lord Ashdown Charitable Settlement for financial support, $\mathrm{Dr}$ Richard Stone and John Hall for their assistance, and to Jane Wadsworth for advice on statistical analysis.

1 Department of Environment. Homelessness statistics: England. London: HMSO, 1990.

2 Lowry S. Health and homelessness. BMF 1990; 300: 32-4.

2 Lowry S. Health and homelessness. BMF $1990 ; 300: 32-4$. Wilson TD. Health research among the homeless. London:
London School of Hygiene and Tropical Medicine, 1985. (MSc thesis.)

4 Audit Commission. Housing the homeless: the local authority role. London: HMSO, 1989.

5 Drennan V, Stearn J. Health visitors and homeless families. Health Visitor 1986; 59: 340-2.

6 Health Visitors' Association and the General Medical Services Committee. Homeless families and their health. London: British Medical Association, 1989

7 Conway J, ed. Prescription for poor health: the crisis for homeless Conway J, ed. Prescription for poor health: the crisis for homed

families. London: London Food Commission, 1988.
8 Maclure A, Stewart GT. Admission of children to hospital Maclure A, Stewart GT. Admission of children to hospital
in Glasgow: relation to unemployment and other deprivain Glasgow: relation to unemployment

9 Victor CR, Connelly J, Roderick P, Cohen C. Use of hospital services by homeless families in an inner London health district. $B M F$ 1989; 299: 725-7.

10 Heaton PA, Charlton TL. Burns affecting children from homeless families. Fournal of Maternal and Child Health 1993; 18: 16-21.

11 Beautrais AL, Fergusson DM, Shannon FT. Family life events and behavioural problems in preschool-aged children. Pediatrics 1982; 70: 774-9.

12 Zigmond AS, Snaith RP. The hospital anxiety and depression scale. Acta Psychiatr Scand 1983; 67: 361-70.

13 Richman S, Roderick P, Victor CR, Lissauer T. Use of acute hospital services by homeless children. Public Health 1991; 105: 297-302.

14 Victor CR. Health status of the temporary homeless population and residents of North West Thames region. population and residents

15 Brown G, Hairs T. Social origins of depression. London: Tavistock Publications, 1978.

16 Moss P, Plewis I. Mental distress in mothers of preschool children in inner London. Psychol Med 1977; 7: 641-52.

17 Murray L, Cooper PJ, Stein A. Postnatal depression and infant development. BMF 1991; 302: 978-9.
18 Rutter M. Parental mental disorder as a psychiatric risk factor. In: Hales RE, Frances AJ, eds. American Psychiatric Association Annual. Vol 6. Washington: American Psychiatric Press, 1987: 647-63.

\section{Commentary}

Alongside the rapid increase in poverty now affecting between a quarter and a third of UK children, ${ }^{1}$ the 1980 s have seen the development of the related and disturbing phenomenon of homelessness among families with young children. ${ }^{2}$ The rise has continued into the 1990s with 101205 households with dependent children registered homeless in 1990 compared with 89981 in $1989 .{ }^{3}$ Children are the single most affected group; it is estimated that between 200000 and 250000 are living in temporary accommodation. ${ }^{2}$ The low level of new council housing starts combined with the loss of rented housing stock through council house sales and the effects of the recession ${ }^{4}$ are likely to ensure further rises in homeless families in the future.

\section{Why study homelessness and health?}

As Lissauer et al note in this paper, adverse effects of homelessness on children's health have been reported but most have been uncontrolled studies based on anecdote. The homeless are likely to represent some of the most materially and socially deprived families in the country $^{1}$ and the health experience of their children might provide a further insight into the adverse effect of deprivation on child health. Many data related to the extent of health inequalities are based on measures of socioeconomic status which inadequately reflect differences in material and social resources. ${ }^{5}$ The remarkable difference in mean gross earned income between the homeless and the housed reported by Lissauer et al serves to illustrate this point particularly when we consider that the control group is itself relatively deprived.

The St Mary's group, by comparing the process of hospital admission and illness severity of homeless and housed children, have started the difficult task of studying the difference in the illness experience of homeless children. Hospital admission in childhood is linked to deprivation ${ }^{6}$ and reflects both an increase in admission for mainly social reasons and for established pathology. ${ }^{7}$ However, hospital admission remains a partial and incomplete proxy for childhood morbidity.

\section{Problems of method}

Lissauer $e t$ al's work illustrates the difficulties involved in studying the effects of a complex social phenomenon such as homelessness. Homelessness is part of multiple deprivation and it is difficult to disentangle the effect of the loss of a permanent home from the multitude of other factors adversely influencing health outcomes. It could be argued that many of the families were seriously disadvantaged before being rendered homeless and a significant percentage were recent immigrants, many escaping oppression, famine, and war. Thus 
the comparison of the homeless group with the controls was not a comparison of 'like with like' making conclusions related to the specific effects of homelessness problematic.

The use of housed children experiencing hospital admission as the control group does not allow the authors to comment on the admission experience of homeless children compared with the rest of the child population; the housed children are likely themselves to represent a deprived group for the reasons stated above. However, the method does permit comment on differences in illness severity and the relative influence of social factors on admission. A more comprehensive study design including a second control group of children not experiencing admission would have provided data on the hospital admission experience of homeless children compared with the child population.

The study also suffers from relatively small numbers; it is possible that, with larger numbers, the significance of the deaths occurring exclusively in the homeless group may have been clarified. This problem and that of a narrow focus on hospital admission as the only measure of morbidity may be overcome by a prospective longitudinal cohort design, though this would be far more time consuming and expensive.

The researchers have stepped bravely into the measurement of decision making by admitting medical staff and grading illness severity. A measurement of both these dimensions is important in studying childhood hospital admissions; however, their measurement is problematic and the researchers have not given sufficient information on the questionnaires used to allow comment on their validity.

\section{Further study of homelessness and health} There can be no doubt that homelessness and its effect on child health is an important area for further study. Many of the problems of method encountered in the St Mary's study could be overcome by a prospective longitudinal cohort design based on a number of centres. Such a study should explore morbidity more comprehensively than hospital admission and include use of primary care and preventive services and psychological and behavioural morbidity. Wilkinson points out that poverty has its effect on health not simply through lack of income but also through the psychological effects of powerlessness and isolation; the homeless are likely to suffer these in greater measure than most other groups. ${ }^{8}$ The longitudinal design would permit the long term effects of periods of homelessness to be assessed as well as the short term effects such as those demonstrated in Lissauer et al's study.

Though anecdote is inadequate for reaching clear conclusions related to the true effects of homelessness on health, the power of qualitative data in illuminating the 'cold' figures and generating hypotheses should not be ignored. It is worth finishing with some quotes from mothers of homeless families that serve to illustrate the privations which homelessness imposes ${ }^{9}$ : 'There's only one cooker between about 130 people ... and if you do start cooking and then go back to your room then your dinner either gets burnt or stolen.' 'My daughter has been scalded and other children have had electric shocks. In your own home you can be careful, have gates across doorways, etc, but in a hotel you've got to put up with other people being careless'.

N J SPENCER

School of Postgraduate Medical Education, University of Warwick, Coventry CV4 $7 A L$

1 Bradshaw J. Child poverty and deprivation in the UK. London: National Children's Bureau, 1990.

2 Department of Environment. Homelessness statistics: England. London: HMSO, 1990.

3 National Children's Home. The NCH factfile: children in Britain 1992. London: National Children's Home, 1992. 4 Lowry S. Housing and health. London: BMJ Publications, 1991.

5 Davey-Smith G, Bartley M, Blane D. The Black report on socioeconomic inequalities in health 10 years on. $B M \mathcal{F}$ 1990; 301: 373-7

6 Spencer N, Lewis $\dot{M}$. Multiple admissions under 2 years of age. Arch Dis Child 1991; 66: 938-41.

7 Spencer NJ, Lewis MA, Logan S. Multiple admission and deprivation. Arch Dis Child 1993; 68: 760-2.

8 Wilkinson R. Income distribution and mortality: a natural experiment. Sociology of Health and Illness 1990; 12: experimen.

9 Bayswater Hotel Homelessness Project. Speaking for ourselves: families in Bayswater $B \mathcal{E} B$. London: Bayswater Hotel Homelessness Project, 1987. 